\title{
Two-dimensional electrophoresis of proteins as a source of monogenic and codominant markers for population genetics and mapping the expressed genome
}

\author{
D. DE VIENNE*, J. BURSTIN, S. GERBER†, A. LEONARDI, M. LE GUILLOUX,

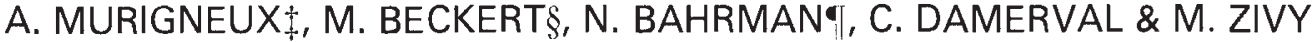 \\ Station de Génétique Végétale, INRA/CNRS URA 1492/Université Paris XI, La Ferme du Moulon, 91190 Gif s/Yvette, \\ $\dagger$ INP-ENSAT, 145 Avenue de Muret, 31076 Toulouse Cedex, $₫$ BIOCEM, Laboratoire de Biologie Cellulaire et \\ Moléculaire, Campus Universitaire des Cézeaux, 24 Avenue des Landais, 63170 Aubière, \$INRA, Domaine de \\ Crouëlle, 63039 Clermont-Ferrand Cedex and ๆ/NRA, Station de Recherches Forestières de Bordeaux-Cestas, \\ Laboratoire de Génétique et Amélioration des Arbres Forestiers, BP 45, 33611 Gazinet Cedex, France
}

\begin{abstract}
The positional polymorphism of polypeptides revealed using two-dimensional polyacrylamide gel electrophoresis (2-D PAGE) was analysed in segregating families of four plant species, a gymnosperm (maritime pine), and three angiosperms (maize, barley and pea). All of the 170 variations scored had monogenic and codominant inheritance, making 2-D PAGE a quite abundant and cheap source of good-quality genetic markers. Genetic mapping showed that the loci involved are well distributed on the chromosomes. In particular, the construction of a composite map of the maize genome including 253 markers revealed that the protein loci are interspersed with the RFLP loci, and provide in some instances markers for chromosomal regions previously lacking molecular markers. In the context of the genome mapping projects, such markers are physiologically relevant in that they reveal loci whose transcripts are translated in the organ analysed.
\end{abstract}

Keywords: genome mapping, isoelectric point variation, protein markers, RFLPs, two-dimensional electrophoresis.

\section{Introduction}

Two-dimensional polyacrylamide gel electrophoresis (2-D PAGE), which separates polypeptides according to two independent criteria, charge (pI) and molecular weight ( $\mathrm{Mr}$ ), is a powerful technique for analysing complex mixtures of denatured proteins (O'Farrell, 1975). Nonspecific staining or autoradiography can reveal hundreds of gene products simultaneously. The fields of application of this technique are numerous. For instance, in plants, 2-D PAGE is the technique of choice for detecting and quantifying modifications of genome expression under different stresses or in response to hormones, pathogenic infections and symbiosis (e.g. Ferullo et al., 1994; reviewed by Damerval et al., 1988). Molecular analysis of the responsive proteins can be

*Correspondence. undertaken, using methods for obtaining $\mathrm{N}$-terminal or internal amino acid sequence information from microgram amounts of protein in a single spot (Bauw et al., 1992; Komatsu et al., 1993; Touzet et al., 1995).

Assessment of genetic polymorphism using 2-D PAGE has not been widely reported. The variability within and between species has been investigated by comparing 2-D gels in Drosophila (Spicer, 1988), mice (Klose, 1982), cheetahs (O'Brien et al., 1983), primates (Goldman et al., 1987; Janczewski et al., 1990), wheat (Zivy et al., 1984; Bahrman et al., 1988a,b; Thiellement et al., 1989; Zivy et al., 1995), barley (Görg et al., 1992), sugarcane (Ramagopal, 1990), maize (Higginbotham et al., 1991; Burstin et al., 1994), maritime pine (Bahrman et al., 1994; Bahrman \& Petit, 1995) and Globodera (Bossis \& Mugniéry, 1993). The inheritance of position shifts of some polypeptides has been studied in beans 
(Brown et al., 1981), mice (Racine \& Langley, 1980a; Neel et al., 1985) and humans (Rosenblum et al., 1983). In all cases a simple inheritance was found.

Compiling both published and unpublished data from four plant species, one gymnosperm and three angiosperms, we show in this paper that 2-D PAGE can actually be a relevant source of monogenic and codominant markers. Provided a high-resolution technique is used, these markers can be quite numerous, and are useful for any genetic application, from diversity studies to genome mapping. Moreover, because 2-D PAGE reveals the coding regions of the genome, it may prove to be a key technique for the development of maps of expressed genes. A dense genetic linkage map of the maize genome, including both protein and molecular markers, is presented.

\section{Materials and methods}

\section{Genetic material}

In maritime pine (Pinus pinaster Ait.), the analyses were performed on the megagametophyte, the haploid storage tissue of the seed, resulting from the development of a single megaspore. Results from two experiments were used, one involving 56 megagametophytes from a single pine tree of Italian origin (Bahrman \& Damerval, 1989), the other involving 222 megagametophytes from 18 trees from the Landes population (France), with an average of 12 megagametophytes for each tree analysed (Gerber et al., 1993).

Two pea (Pisum sativum L.) lines, 'Erygel' and '661', developed by the Institut National de la Recherche Agronomique, France, were crossed, and their $F_{1}$ hybrid was self-pollinated to derive an $F_{2}$ population. The 2-D PAGE was performed from leaflets of 30 adult $F_{2}$ plants grown in the field (unpublished).

In maize (Zea mays L.), four experiments were performed from etiolated coleoptiles harvested on seedlings grown in the dark at $24^{\circ} \mathrm{C}$ for 8 days. The material was: (1) 85 plants of an $F_{2}$ progeny between the French flint line 'F2', and an American line of the Iodent group, encoded 'Io' (Damerval et al., 1994); (2) 46 microspore-derived doubled haploid $(\mathrm{DH})$ lines, obtained from an $\mathrm{F}_{1}$ hybrid between the parental lines DH5 and DH7 (Murigneux et al., 1993a,b); (3) 21 lines, representative of the variability used for hybrid breeding in Europe, and belonging to different kernel types from American and European origins (Burstin et al., 1993); (4) eight lines, also taken from the lines used in Europe (Leonardi et al., 1991).

In barley (Hordeum vulgare L.), the segregating population consisted of $62 \mathrm{DH}$ lines, derived from an $F_{1}$ hybrid between the parental lines 'Kaskade' (Bayer Pflanzenzuchtges, Germany) and 'DH8293' (Florimond Desprez, France). Proteins were extracted from the aerial parts of the seedlings (Zivy et al., 1992).

\section{Protein extraction and 2-D PAGE}

The proteins were extracted from pine megagametophytes as described by Bahrman \& Damerval (1989). They were extracted from pea leaves, maize etiolated coleoptiles and barley seedlings following the procedure described by Damerval et al. (1986). For all the species, the isoelectric focusing and the second (SDS) dimension was performed according to Damerval et al. (1987). The silver staining followed the method of Damerval et al. (1987), with the modifications of Burstin et al. (1993). It is worth noting that the 2-D technique used for these experiments was specially modified to obtain the high resolution and reproducibility required for genetic analysis.

The changes in spot positions were scored visually. Coelectrophoreses 1:1 of samples of the parents of the segregating populations were performed in order to ascertain the differences in spot positions. Systematic replicates of gels did not prove to be necessary with our high-resolution gels.

\section{Restriction fragment length polymorphism (RFLP)}

The RFLP and mapping techniques used for the maize $\mathrm{F}_{2}$ and $\mathrm{DH}$ populations are described, respectively, by Damerval et al. (1994) and Murigneux et al. (1993a).

\section{Results}

\section{Genetic bases of the position shifts}

Haploid and doubled haploid progeny In the haploid (pine) or doubled haploid (barley and maize) segregating populations, apparent position shifts of protein spots were observed (Fig. 1a). Position shifts were those cases where two spots, with similar aspects and located close to each other, were mutually exclusive between the parents and among the offspring, i.e. were never both present or both absent in any given genotype. Twenty-two such situations were counted in the barley population, 23 
in the maize $\mathrm{DH}$ population and 29 in the pine megagametophyte population from the single tree. That observation can be readily explained by the action of biallelic loci determining pI (horizontal shifts) and/or apparent $\mathrm{Mr}$ (vertical shifts) modifications of the polypeptides. Assuming this monogenic inheritance, 1:1 segregations of the spot positions were found, with only rare segregation distortions, except for the DH barley population (Zivy et al., 1992).

Among the megagametophytes of the 18 unrelated trees, more than two spots could be found which were mutually exclusive, which was as expected with possible multiallelic loci. Thirty-five putative loci were found: in addition to 19 biallelic loci, 12 triallelic loci, 2 four-allelic loci including a silent allele, 1 five-allelic locus including a silent allele and 1 six-allelic locus were detected (Gerber $e t$ al., 1993).

$F_{2}$ progeny In the $\mathrm{F}_{2}$ populations of maize and pea, 1: $2: 1$ segregations of the position shifts were observed, i.e. in addition to the two parental positions, $F_{1}$-type patterns (with the two spots) were observed for about half of the individuals (Fig. 1b). In maize, 42 pairs of such monogenic positional variants were observed, and 19 in pea (Table 1 and Fig. 2). Again, the number of segregation distortions
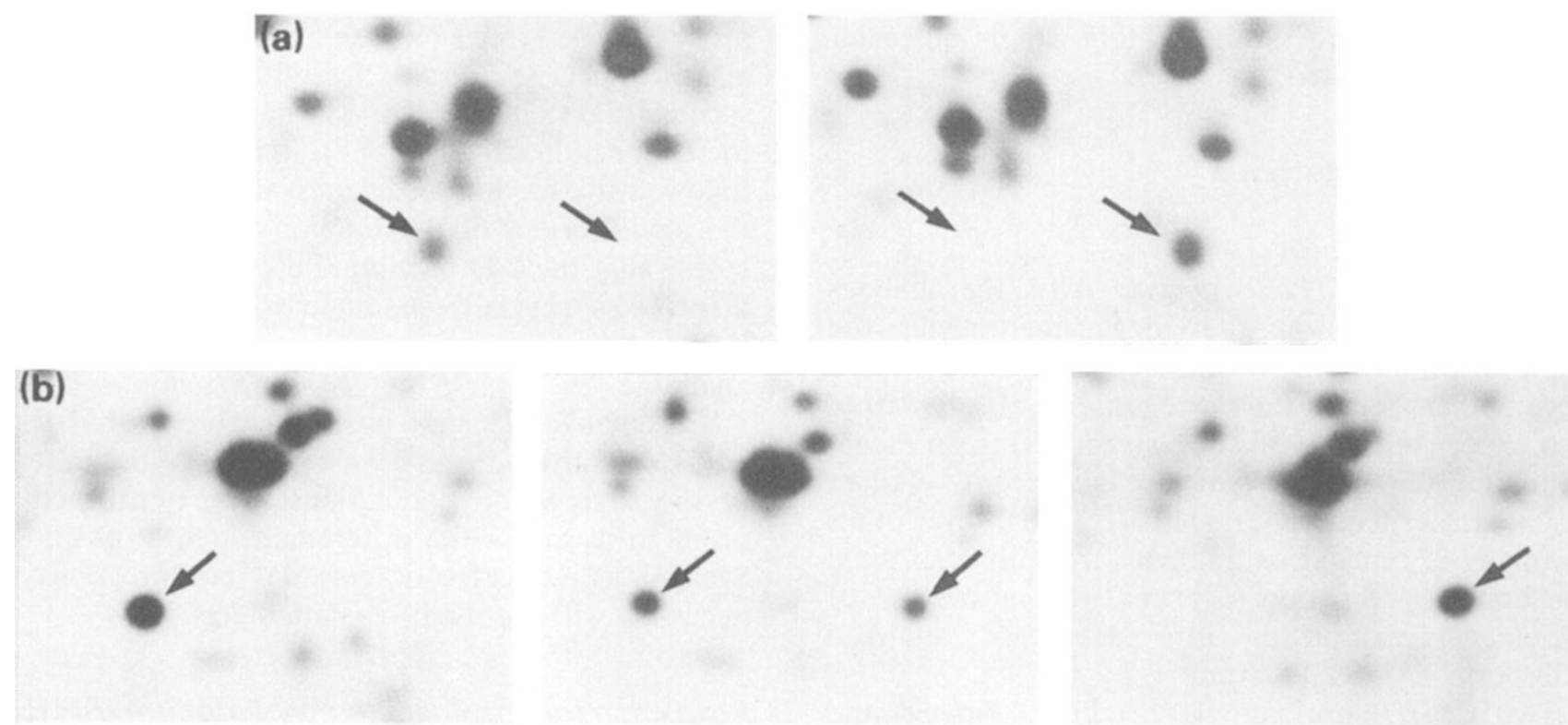

Fig. 1 Typical position shifts of polypeptide spots observed in a doubled haploid population of barley (a), and in an $F_{2}$ population of pea (b). In the $\mathrm{F}_{2}$ population, an $\mathrm{F}_{1}$-type pattern is observed in addition to the parental-type patterns.

Table 1 Plant material and numbers of positional variants

\begin{tabular}{lccc}
\hline Species & Material & Number of positional variants & References \\
\hline Pea & $30 \mathrm{~F}_{2}$ plants & 19 pairs & Unpublished \\
Barley & $62 \mathrm{DH}$ lines & 22 pairs & Zivy et al. $(1992)$ \\
Maize & $85 \mathrm{~F}_{2}$ plants & 42 pairs & Damerval et al. $(1994)$ \\
& $46 \mathrm{DH}$ lines & 23 pairs & Unpublished \\
& 8 lines & 22 pairs, 9 triplets, 1 quadruplet & Leonardi et al. $(1991)$ \\
& 21 lines & 50 pairs, 12 triplets, 7 quadruplets, & Burstin et al (1994) \\
Pine & 56 megagametophytes from & 1 sextuplet & \\
& a single tree & 29 pairs & Bahrman \& Damerval (1989) \\
& 222 megagametophytes from & 19 pairs, 12 triplets, 2 quadruplets, & Gerber et al. $(1993)$ \\
& 18 unrelated trees & 1 quintuplet, 1 sextuplet & \\
\hline
\end{tabular}




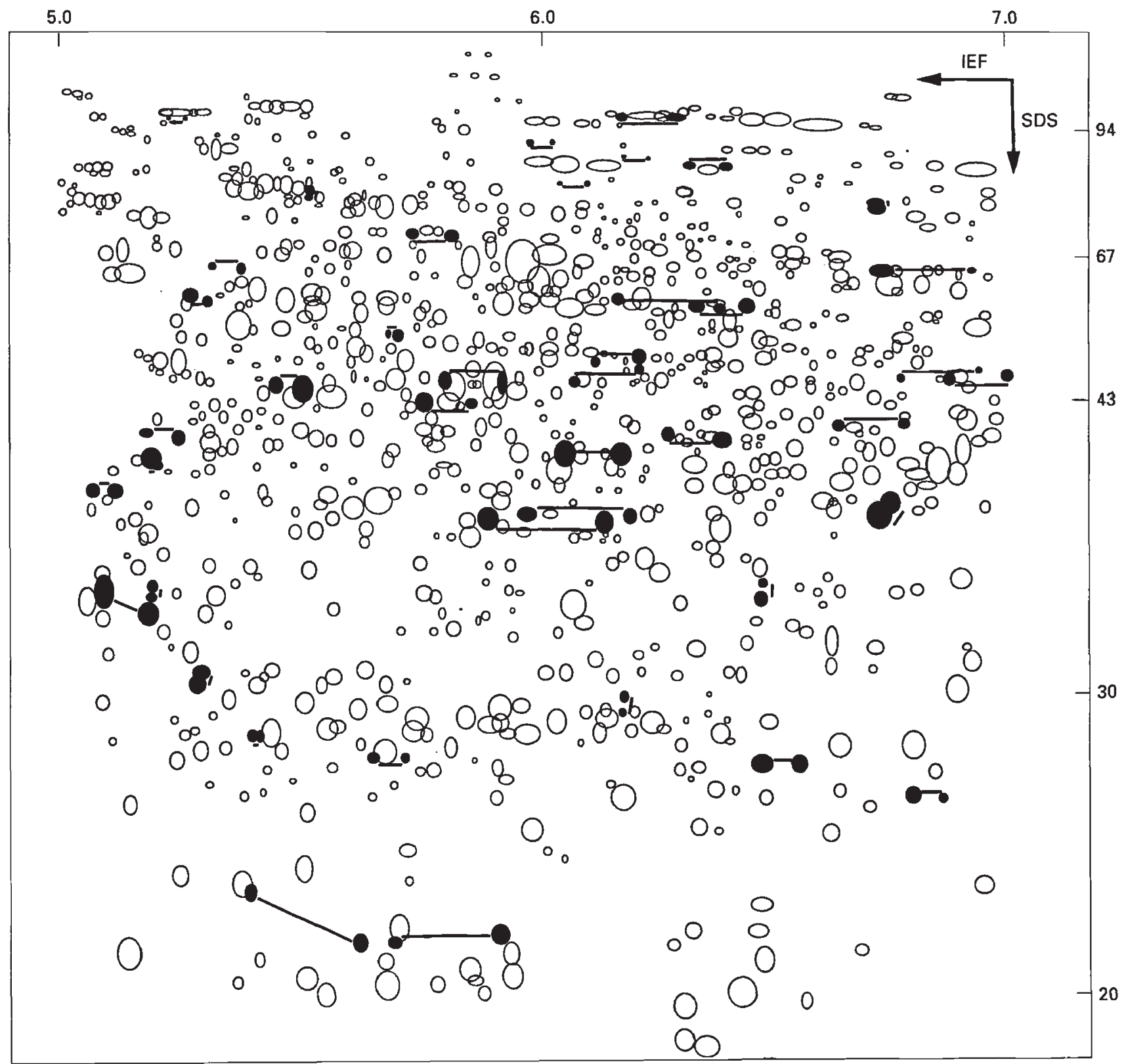

Fig. 2 Schematic representation of the 42 position shifts observed between the two maize lines analysed. The allelic spots are joined with a line.

was not much higher than expected by chance (nine out of 61). In maize these values are similar to those obtained with other types of markers such as RFLPs or isozymes.

\section{Genetic mapping}

Most of the polymorphic loci detected by 2-D PAGE in the different species could be genetically mapped. Using the MAPMAKER 2.0 computer pro- gram (Lander et al., 1987), two linkage maps of the maize genome were constructed, which included both RFLP and protein position shift loci. From the cross 'Io' $\times$ ' $F 2$ ', 39 of the 42 position shift loci were mapped in addition to 70 RFLP loci of the maize reference map (Gardiner et al., 1993). From the cross 'DH5' $\times$ 'DH7', 23 position shifts and 125 RFLP loci were mapped. Using as anchor markers 13 protein loci and 29 RFLP loci common to the two maps, a composite genetic map which included 

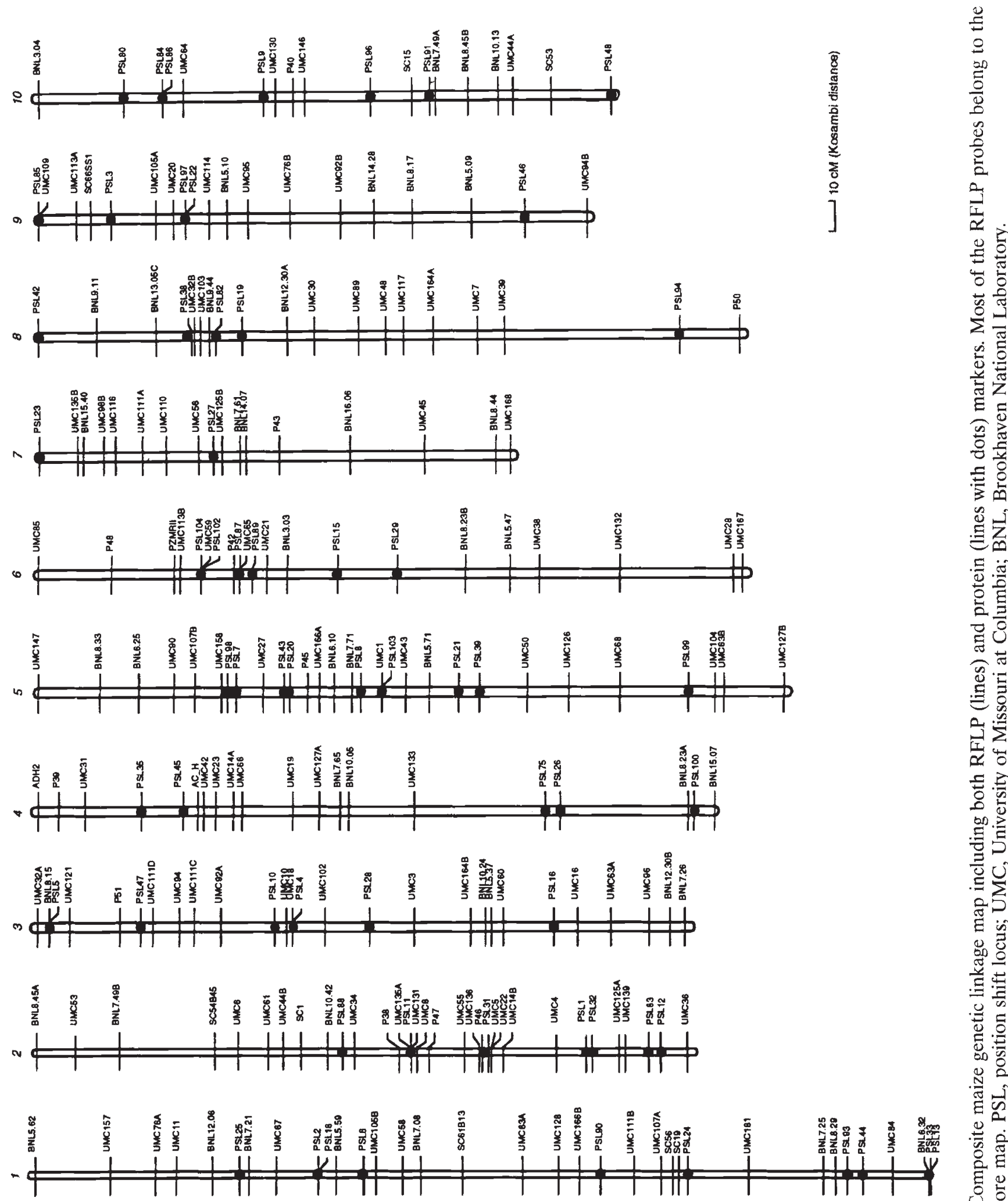
253 marker loci was constructed with the program JoinMap (Stam, 1993) (Fig. 3). The protein loci were found on each of the 10 chromosomes, interspersed with the RFLP loci. Five of the 13 anchor protein loci had the same two alleles in both populations, whereas eight had three alleles. As compared to the maize core map (Gardiner et al., 1993), at least seven protein loci (PSL44 and PSL33/13 on chromosome 1, PSL1 and PSL32 on chromosome 2, PSL21, PSL39 and PSL99 on chromosome 5) marked regions without RFLP markers. More interestingly, a protein locus (PSL13/33) allowed chromosome 1 to be continued about $10 \mathrm{cM}$ beyond the probe BNL6.32, while another one (PSL48) allowed chromosome 10 to be continued about $30 \mathrm{cM}$ beyond the probe UMC44 A, the most distal probe of the core map, and $13 \mathrm{cM}$ beyond $\mathrm{SC} 53$, a ribosomal protein probe.

The partial genetic map constructed from barley DH lines included 15 of the 22 protein loci, organized into five linkage groups (Zivy et al., 1992). In pine, the 29 loci from the single tree data could be mapped into six linkage groups in a map including other marker loci. Finally, using mapping methods developed in human genetics for data from unrelated families (Lander \& Green, 1987), 28 out of the 35 position variants observed in the composite pine population could be mapped into 14 linkage groups. In the pea, 13 of the 19 position shift loci were mapped into nine linkage groups (not shown). Unmapped loci are likely to be because of insufficient saturation of the maps.

\section{Allelic diversity}

All of the 170 position shifts found in the different species proved to be monogenically inherited. One can therefore be confident in using these variations to estimate the allelic diversity. In a population of 21 maize lines of different origins (see Materials and methods), 50 pairs, 12 triplets, seven quadruplets and one sextuplet of spots which were mutually exclusive were observed, corresponding to 70 putative polymorphic loci. Including a silent allele, the mean number of alleles per polymorphic locus was 2.4 among these lines. In the same material, the mean number of alleles per enzyme locus was found to be 2.2 (14 polymorphic loci analysed). In a previous study, Leonardi et al. (1991) detected 22 pairs, nine triplets and one quadruplet in a set of eight maize lines covering a similar range of variation, which resulted in a value of 2.3 alleles per locus. Among the 18 pines from the Landes population, 2-6 alleles per polymorphic locus (a mean of
2.7) were found. Among six populations from various origins, including the Landes one, Petit et al. (1995) found 2.1 alleles per polymorphic locus with 2-D PAGE, and 2.5 with isozymes.

\section{Analysis of the position shifts}

In the four species studied, there were many more pI changes (horizontal shifts) than $\mathrm{Mr}$ changes (vertical shifts) (Fig. 2). For the horizontal shifts, the distances between the two members of a pair are larger for the low than for the high Mr proteins, and the percentage of variation is higher for the large than for the small proteins. This has been shown statistically in maritime pine (Bahrman \& Petit, 1995). Observations on wheat storage proteins by Anderson et al. (1985), who described series of allelic spots equally spaced along the horizontal direction, are not confirmed on our materials: even within a given $\mathrm{Mr}$ class, the allelic shifts did not display any clear periodicity (Fig. 2). Actually, there is no theoretical reason for such a phenomenon: simulations of iterative substitutions of amino acids for three different proteins show that the pI shifts, computed as in the Bisance server (Dessen et al., 1990), do not vary linearly, and depend on the substituted amino acid, the $\mathrm{Mr}$ of the protein and the amino acid composition (Fig. 4).

\section{Discussion}

\section{Molecular bases of allelic position shifts}

Apparent modifications of $\mathrm{pI}$ and/or $\mathrm{Mr}$ of proteins revealed by $2-\mathrm{D}$ gels have long been described in various species (reviewed in Damerval et al., 1988), but no systematic study of the genetic bases and possible applications of this source of markers is available. Combining the 2-D data from eight experiments in four plant species, 272 proteins were found which displayed apparently variable positions, with two to six variants per protein. For 170 variable proteins detected in segregating populations, the Mendelian analysis consistently revealed a monogenic and codominant control, and allowed the responsible loci to be included in genetic maps.

These electrophoretic variations may have three explanations. (1) The members of a pair are coded by different genes, whose products are mutually exclusive, because either of tight linkage of genes in repulsion, or of regulatory mechanisms. In fact, sequencing members of allelic pairs has revealed that they correspond in almost all cases to the same protein (Touzet et al., 1995). (2) There are monog- 

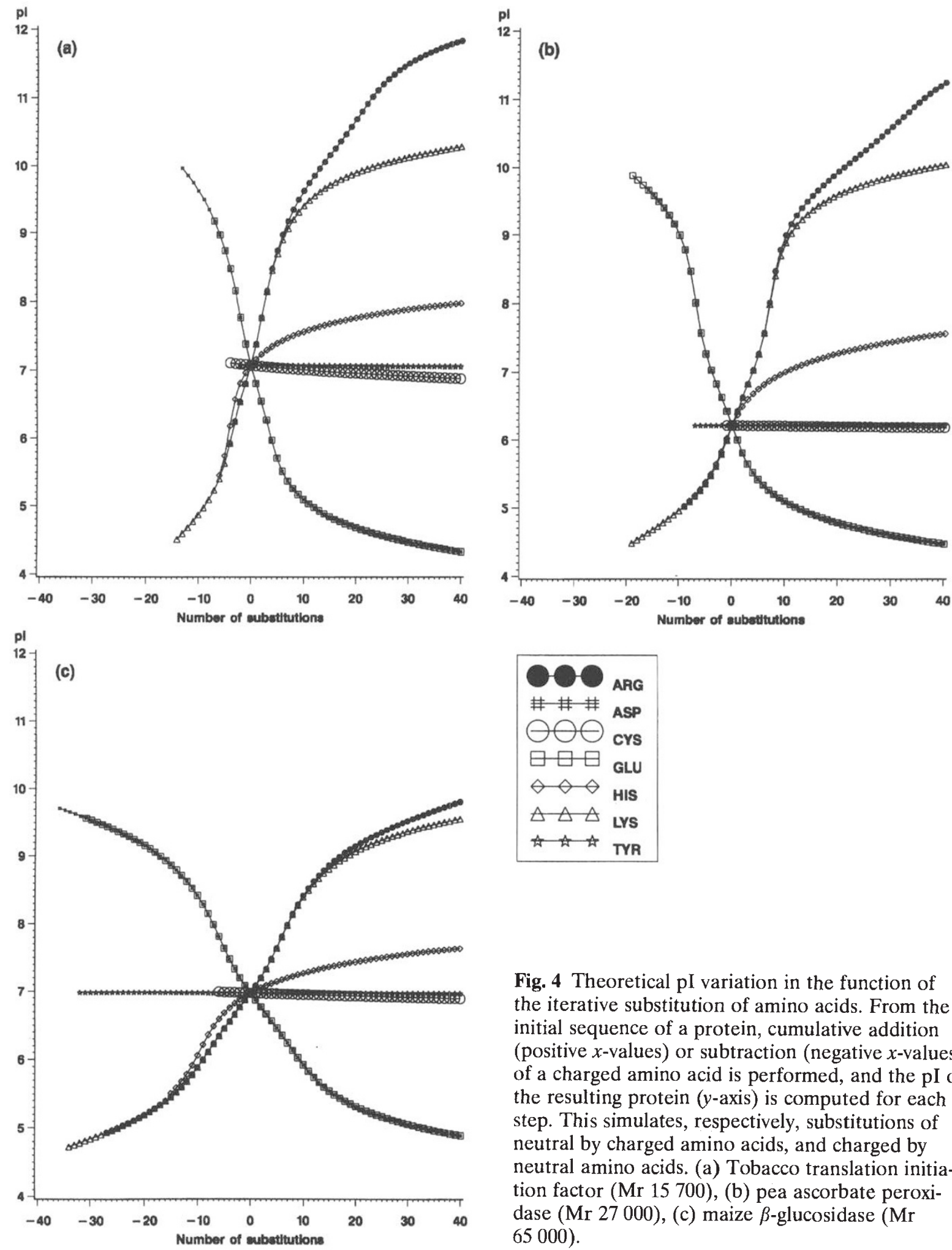

Fig. 4 Theoretical pI variation in the function of the iterative substitution of amino acids. From the initial sequence of a protein, cumulative addition (positive $x$-values) or subtraction (negative $x$-values) of a charged amino acid is performed, and the $\mathrm{pI}$ of the resulting protein ( $y$-axis) is computed for each step. This simulates, respectively, substitutions of neutral by charged amino acids, and charged by neutral amino acids. (a) Tobacco translation initiation factor (Mr 15 700), (b) pea ascorbate peroxidase (Mr 27000$)$, (c) maize $\beta$-glucosidase $(\mathrm{Mr}$ $65000)$. 
enic co- or post-translational modifications of a protein. Even though such modifications are common for plant proteins, they could explain the observed variations only if the product of the polymorphic modifier gene is limiting, because codominant inheritance was consistently found. To our knowledge, such a mechanism has never been demonstrated. (3) There are allelic differences in the primary structure of a protein (substitutions, additions/deletions). If we refer to the isozyme literature, it appears that the codominant mobility differences between allozymes consistently result from variations in the structural genes (discussed by Coyne, 1982). This was shown for ADH in Drosophila (Thatcher, 1980) and maize (Osterman \& Dennis, 1989), xanthine dehydrogenase in Drosophila (Gelbart et al., 1976), sn-glycerol-3-phosphate dehydrogenase in Drosophila (Kusakabe et al., 1990), $\beta$-glucuronidase in the mouse (Lusis \& Paigen, 1978), etc. Finally, the higher percentage of variations for large than for small proteins is easier to explain in the context of structural variations, because of the relationship between the length of the molecules and the substitution rates (Nei, 1987). Thus it is likely that in most instances, if not all, the position shift loci correspond to the structural genes of the proteins.

\section{Types of position shifts}

There are significantly more pI (horizontal shifts) than $\mathrm{Mr}$ changes (vertical shifts), as already mentioned by Anderson et al. (1985) for wheat grain proteins. It is worth noting that $\mathrm{Mr}$ changes may be actual (e.g. Belanger \& Kriz, 1991), but single amino acid substitution can influence mobility in the SDS dimension, giving rise to apparent $\mathrm{Mr}$ shifts (e.g. Noel et al., 1979). In any case, there would be greater selective constraints against the mutations affecting the size of the polypeptides than those changing the charge. If we consider the horizontal shifts, the greater distances between the two spots of a pair for the low $\mathrm{Mr}$ proteins were expected because a given charge variation has a relatively higher effect for the small than for the large proteins (Fig. 4).

\section{Amount of polymorphism}

Because 2-D PAGE allows several hundreds of proteins to be separated, it was greeted with initial optimism by geneticists. However, the first results have shown consistently less variability than one dimensional (1-D) PAGE surveys of isozyme varia- tion in humans (McConkey et al., 1979; Walton et al., 1979; Smith et al., 1980), mice (Racine \& Langley, 1980b), and Drosophila (Leigh Brown \& Langley, 1979). Moreover it was shown in rodents that isozyme and 2-D estimates of genetic distances between species were strongly correlated (Aquadro \& Avise, 1981). Given that 2-D analysis was claimed to be tricky and time-consuming, and with the development of the RFLP technique which provides a virtually unlimited number of markers (Botstein $e t$ al., 1980), use of 2-D PAGE in genetics has become quite limited.

The reasons why 2-D PAGE should reveal low levels of polymorphism are well-known. Because of denaturation and nonspecific staining, a large proportion of abundant, nonsoluble proteins would be revealed, many of them being supposedly derived from complex structures. Interaction between molecules places constraints on the number of mutations that can be retained. Moreover, even the abundant proteins not involved in superstructures would be less variable than soluble, low-abundant enzymes (Singh \& Coulthart, 1982). On the other hand, in addition to unit charge substitutions, nondenaturing 1-D gels have been shown to reveal conformational differences. Denaturing the proteins would result in the loss of site-specific influences on ionization (reviewed by Damerval et al., 1988).

However, our results do not seem to be consistent with such a discrepancy between both techniques. In maize as well as maritime pine, the number of alleles per polymorphic locus was similar for isozymes and 2-D PAGE. The genetic materials used in the different species do not allow the polymorphism rates to be computed. However, it is worth noting that in the pea, which is known to be not very polymorphic, 4 per cent of the proteins were variable between the two parental lines. A similar percentage was found in barley. In maize and pine, where 21 and 8 individuals were analysed, respectively, around 10 per cent of the polypeptides displayed positional variation. These values are in the range of the polymorphism frequencies classically observed with isozymes in natural populations (Nevo et al., 1984). The species analysed were taxonomically diverse, including two monocotyledons, one dicotyledon and one gymnosperm, making the results of probable general value. In addition to technical improvements (Rosenblum et al., 1983; Damerval et al., 1986), there would be at least three reasons for these relatively 'high' levels of polymorphism: (1) 2-D PAGE does not only reveal unit charge substitutions, but also other variations not detectable by 1-D PAGE (discussed by Neel, 1990); 
(2) in contrast with previous results (e.g. Singh \& Coulthart, 1982), neither the insolubility nor the abundance of the polypeptides seem to be factors decreasing the variability, at least in maize (Damerval, 1994); (3) the majority of proteins revealed are not structural ones: partial sequencing of 36 major proteins excised from the gels has shown that most of the significant homologies are with enzymes ( $\mathrm{P}$. Touzet, in preparation).

\section{Increasing the number of loci revealed}

The number of loci revealed by 2-D PAGE could be increased as follows. (1) The new 2-D technique using an immobilized $\mathrm{pH}$ gradient in the first dimension improves reproducibility and resolution, and hence could increase the number of loci retained (Görg et al., 1992). (2) In addition to the position shifts, presence/absence variations of some proteins can be detected. These variations are ambiguous, because they may correspond either to quantitative differences with a spot below the level of detection, or to position shifts where a member of the pair is not detected. Nevertheless, their genetic base can be monogenic, and thus they can be used as dominant markers (Bahrman \& Damerval, 1989). (3) In the experiments described, the proteins from only one organ were analysed. It is well documented, in plants as well as in animals, that polymorphism is higher for organ-specific than for non-organ-specific proteins (Klose, 1982; de Vienne et al., 1988; Bahrman \& Petit, 1995). Analysing some physiologically contrasting organs, such as endosperms, roots, green leaves and pollen, substantially increases the number of polymorphic loci revealed (unpublished results).

\section{2-D PAGE as a specific source of markers}

Why should 2-D PAGE of proteins be a useful source of markers, when RFLP and polymerase chain reaction-based techniques are widely used in a growing number of laboratories, and the restriction landmark genomic scanning method allows thousands of DNA markers to be detected on single 2-D gels (Kawase, 1994)? (1) From the genetic point of view, the position shifts are 'good' markers, because they are monogenic, codominant and locus-specific, and seem to be randomly distributed in the genome. Some extensively used DNA techniques, such as random amplified polymorphic DNAs (Williams et al., 1990), do not have most of these qualities. Moreover, the position shift polymorphism is expected to be selectively neutral to a large extent, as is enzyme polymorphism. This is consistent with the high correlation between the pedigree distance found by Burstin et al. (1994) in their set of 21 maize lines and the Rogers's distance computed from the position shift loci $(r=0.83)$. (2) Previous screening of the informative loci is not required, unlike RFLPs or microsatellites. All the proteins obtained after a denaturing, versatile extraction are revealed in a single gel, i.e. dozens of loci can be genotyped in a single experiment, making the 'locus cost' less than with RFLPs. (3) The protein markers reveal translated regions of the genome, making the maps constructed with position shift loci useful tools for physiological and molecular studies. Whenever a cDNA probe detects several loci, which is common in large-genome species, such as maize, Brassica, etc., the colocation of a position shift locus with one of the cDNA loci indicates that this cDNA locus is expressed and translated in the organ considered. It must be pointed out that even though technologies based on the specificity of the 3' untranslated part of the cDNAs may indicate the transcribed loci, the 2-D PAGE alone gives access en masse to the translated loci. Of course this strategy requires large-scale identification of the proteins in 2-D gels, which is now possible using microsequencing. Such programs are in progress in man, rat, mouse, E. coli (Celis, 1993), rice (Komatsu et al., 1993; Tsugita et al., 1994), yeast (Garrels et al., 1994), Arabidopsis (Bauw et al., 1992) and maize (P. Touzet et al., submitted), and should become faster and more reliable in the future thanks to amino acid composition analysis and mass spectrometry.

\section{Acknowledgements}

We wish to thank Dr R. Petit for his careful reading of the manuscript, Dr E. Dirlewanger for the pea material, and J. Blaisonneau for expert technical assistance. This work was in part supported by a grant from the GIP GREG (Ministère de l'Education Nationale et de la Recherche, France).

\section{References}

ANDERSON, N. G., TOllaksen, S. L., PASCOE, F. H. AND ANDERSON, L. 1985. Two-dimensional electrophoretic analysis of wheat seed proteins. Crop Sci. 25, 667-674.

AQUADRO, C. F. AND AVISE, J. C. 1981. Genetic divergence between rodent species assessed by using two-dimensional electrophoresis. Proc. Natl. Acad. Sci. U.S.A., 78, 3784-3788.

BAHRMAN, N. AND DAMERVAL, C. 1989. Linkage relationships of loci controlling protein amounts in maritime 
pine (Pinus pinaster Ait.). Heredity, 63, 267-274.

BAHRMAN, N. AND PETIT, R. 1995. Genetic polymorphism in maritime pine (Pinus pinaster Ait.) assessed by two-dimensional gel electrophoresis of needle, bud and pollen proteins. J. Mol. Evol., (in press).

BAHRMAN, N., ZIVY, M. AND THIELLEMENT, H. 1988 a. Genetic relationship in the Sitopsis section of Triticum and the origin of the B genome of polyploid wheats. Heredity, 61, 473-480.

BAHRMAN, N., CARDIN, M.-L., SEGUIN, M., ZIVY, M. AND THIELLEMENT, H. 1988b. Variability of 3 cytoplasmically encoded proteins in the Triticum genus. Heredity, 60 , 87-90.

BAHRMAN, N., ZIVY, M., DAMERVAL, C. AND BARADAT, PH. 1994. Organization of the variability of abundant proteins in seven geographical origins of maritime pine (Pinus pinaster Ait.). Theor: Appl. Genet., 88, 407-411.

BAUW, G., VAN MONTAGU, M. AND INZÉ, D. 1992. Microsequence analysis of Arabidopsis proteins separated by two-dimensional polyacrylamide gel electrophoresis: a direct linkage of proteins and genes. In: C. Koncz, N.-H. Chua and J. Schell (eds). Methods in Arabidopsis Research, World Scientific Publishing Co. Pte. Ltd, Singapore.

BELANGER, F. C. AND KRIZ, A. L. 1991. Molecular basis for allelic polymorphism of the maize globulin-1 gene. Genetics, 129, 863-872.

BOSSIS, M. AND MUGNIÉRY, D. 1993. Specific status of six Globodera parasites of Solanaceous plants studied by means of two-dimensional gel electrophoresis with a comparison of gel patterns by a computed system. Fundam. Appl. Nematol., 16, 47-56.

BOTSTEIN, D., WHITE, R. L., SKOLNICK, M. AND DAVIS, R. W. 1980. Construction of a genetic linkage map in man using restriction fragment length polymorphisms. Am. J. Hum. Genet., 32, 314-331.

BROWN, J. W. S., BLISS, F. A. AND HALL, T. C. 1981. Linkage relationships between genes controlling seed proteins in french bean. Theor. Appl. Genet., 60, 251-259.

BURSTIN, J., ZIVY, M., DE VIENNE, D. AND DAMERVAL, C. 1993. Analysis of scaling methods to minimize the experimental variations in 2-D PAGE quantitative data. Application to the comparison of maize inbred lines. Electrophoresis, 14, 1067-1073.

BURSTIN, J., DE VIENNE, D., DUBREUIL, P. AND DAMERVAL, C. 1994. Molecular markers and protein quantities as genetic descriptors in maize. I. Diversity among 21 inbred lines. Theor. Appl. Genet., 89, 943-950.

CELIS J.E (ed.) 1993. Two-dimensional gel protein databases. Electrophoresis, 14, 1089-1240.

COYNE, J. 1982. Gel electrophoresis and cryptic protein variation. Isozymes: Curr. Top. Biol. Med. Res., 6, 1-32.

DAMERVAL, c. 1994. Quantification of silver-stained proteins resolved by two-dimensional electrophoresis: genetic variability as related to abundance and solubility in two maize lines. Electrophoresis, 15, 1573-1579.

DAMERVAL, C., DE VIENNE, D., ZIVY, M. AND THIELLEMENT, H. 1986. Technical improvements in two-dimensional electrophoresis increase the level of genetic variation detected in wheat-seedling proteins. Electrophoresis, 7, $52-54$.

DAMERVAl, C., LE GUillouX, M., BlaisonneaU, J. AND DE VIENNE, D. 1987. A simplification of Heukeshoven and Dernick's silver staining of proteins. Electrophoresis, 8, 158-159.

DAMERVAL, C., ZIVY, M., GRANIER, F. AND DE VIENNE, D. 1988. Two-dimensional electrophoresis in plant biology. Advances in Electrophoresis, 2, 236-340.

DAMERVAl, C., MAURice, A., JOSSE, J. M. AND DE VIENNE, D. 1994. Quantitative trait loci underlying gene product variation - a novel perspective for analyzing regulation of genome expression. Genetics, 138, 1251-1274.

DESSEN, P., FONDRAT, C., VALENCIEN, C. AND MUGNIER, C. 1990. BISANCE: A French service for access to biomolecular sequence data base. Cabios, 6, 355-356.

FERULLO, J. M., NESPOULOUS, L. AND TRIANTAPHYLIDES, C. 1994. Gamma-ray-induced changes in the synthesis of tomato pericarp proteins. Pl. Cell Env. 17, 901-911.

GARDINER, J. M., COE, E. H., MELIA-HANCOCK, S., HOISINGTON, D. A. AND CHAO, s. 1993. Development of a core RFLP map in maize using an immortalized $F_{2}$ population. Genetics, 134, 917-930.

GARRELS, J. I., FUTCHER, B., KOBAYASHI, R., LATTER, G. I., SCHWENDER, B., VOLPE, T., WARNER, J. R. AND MCLAUGLIN, C. V. 1994. Protein identification for Saccharomyces cerevisiae protein database. Electrophoresis, 15, $1466-1486$.

GELBART, W. H., McCARRON, H. AND CHOVNIK., A. 1976. Extension of the limits of the structural element in Drosophila melanogaster. Genetics, 84, 211-232.

GERBER, S., RODOLPHE, F., BAHRMAN, N. AND BARADAT, PH. H. 1993. Seed-protein variation in maritime pine (Pinus pinaster Ait.) revealed by two-dimensional electrophoresis: genetic determinism and construction of a linkage map. Theor. Appl. Genet., 85, 521-528.

GOLDMAN, D., RATHNA GIRI, P. AND O'BRIEN, S. J. 1987. A molecular phylogeny of the hominoid primates as indicated by two-dimensional protein electrophoresis. Proc. Natl. Acad. Sci. U.S.A., 84, 3307-3311.

GÖRG, A., POSTEL, W., BAUMER, M. AND WeIsS, W. 1992. Two-dimensional polyacrylamide gel electrophoresis, with immobilized $\mathrm{pH}$ gradients in the first dimension, of barley seed proteins: discrimination of cultivars with different mating grades. Electrophoresis, 13, 192-203.

HIGGINBOTHAM, J. W., SMITH, J. s. C. AND SMITH, O. s. 1991. Quantitative analysis of two-dimensional protein profiles of inbred lines of maize (Zea mays L.). Electrophoresis, 12, 425-431.

JANCZEWSKI, D. N., GOLDMAN, D. AND O'BRIEN, S. J. 1990. Molecular genetic divergence of orangutan (Pongo pygmaeus) subspecies based on isozyme and two-dimensional gel electrophoresis. J. Hered., 81, 375-387.

KAWASE, M. 1994. Application of the restriction landmark genomic scanning (RGLS) method to rice cultivars as a new fingerprinting technique. Theor. Appl. Genet., 89, 861-864. 
KELly, J. AND FREELING, S. 1980. Purification of maize alcohol dehydrogenase-1 allozymes and comparison of their tryptic peptides. Biochim. Biophys. Acta, 624, $102-110$.

KLOSE, J. 1982. Genetic variability of soluble proteins studied by two-dimensional electrophoresis on different inbred mouse strains and on different mouse organs. $J$. Mol. Evol., 18, 315-328.

Komatsu, s., KaJiWARA, H. AND hIRANO, H. 1993. A rice protein library: a data-file of rice proteins separated by two-dimensional electrophoresis. Theor. Appl. Genet., 86, 935-942.

KUSAKABE, S., BABA, H., KOGA, A., BEWLEY, G. C. AND MUKAI, T. 1990. Gene duplication and concerted evolution of the GPDH locus in natural populations of Drosophila melanogaster. Proc. R. Soc. B., 242, 157-162.

LANDER, E. S. AND GREEN, P. 1987. Construction of multilocus genetic linkage maps in humans. Proc. Natl. Acad. Sci. U.S.A., 84, 2363-2367.

LANDER, E. S., GREEN, P., ABRAHAMSON, J., BARLOW, A., DALY, M. J., LINCOLN, S. E. AND NEWBURG, L. 1987. MAPMAKER: an interactive computer package for constructing primary genetic linkage maps of experimental and natural populations. Genomics, 1, 174-181.

LElGH BROWN, A. J. AND LANGLEY, C. H. 1979. Reevaluation of level of genic heterozygosity in natural population of Drosophila melanogaster by two-dimensional electrophoresis. Proc. Natl. Acad. Sci. U.S.A., 76, 2381-2384.

LEONARDI, A., DAMERVAl, C., HEBERT, Y., GALlals, A. AND DE VIENNE, D. 1991. Association of protein amount polymorphism (PAP) among maize lines with performances of their hybrids. Theor. Appl. Genet., 82, $552-560$.

LUS1S, A. J. AND PAIGEN, K. 1978. The large scale isolation of mouse $\beta$-glucuronidase and comparison of allozymes. J. Biol. Chem., 253, 7336-7345.

McCONKEY, E. H., TAYLOR, B. J. AND PHAN, D. 1979. Human heterozygosity: a new estimate. Proc. Natl. Acad. Sci. U.S.A., 76, 6500-6504.

MURIGNEUX, A., BARLOY, D., LEROY, P. AND BECKERT, M. 1993a. Molecular and morphological evaluation of doubled haploid lines in maize. 1. Homogeneity within DH lines. Theor. Appl. Genet., 86, 837-842.

MURIGNEUX, A., BAUD, s. AND BECKERT, M. 1993b. Molecular and morphological evaluation of doubled haploid lines in maize. 2. Comparison with single-seed-descent lines. Theor. Appl. Genet., 87, 278-287.

NEEL, J. V. 1990. Average locus differences in mutability related to protein "class": A hypothesis. Proc. Natl. Acad. Sci. U.S.A., 87, 2062-2066.

NEEL, J. V., BAIER, L., HANASH, S., ERICKSON, R. P. 1985. Frequency of polymorphism for alleles encoding for liver proteins of domesticated mice. J. Hered., 76, 314-320.

NE1, M. 1987. Molecular Evolutionary Genetics. Columbia University Press, New York.

NEVO, E., BElLEs, A. AND BEN-SHLOMo, R. 1984. The evolu- tionary significance of genetic diversity: ecological, demographic and life history correlates. Lect. Notes in Biomath., 53, 13-213.

NOEL, D., NIKAIDO, K. AND AMES F.-L., G. 1979. A single amino acid substitution in a histidine transport protein drastically alters its mobility in sodium dodecyl sulfatepolyacrylamide gel electrophoresis. Biochemistry, 18, 4159-4165.

O'BRIEN, S. J., WILDT, D. E., GOLdMAN, D., MERRIL, C. R. AND BUSH, M. 1983. The cheetah is depauperate in genetic variation. Science, 221, 459-462.

o'FARRELL, P. H. 1975. High resolution two-dimensional electrophoresis of proteins. J. Biol. Chem., 250, 4007-4021.

OSTERMAN, J. C. AND DENNiS, E. S. 1989. Molecular analysis of the $A D H 1-C^{m}$ allele of maize. Plant Mol. Biol., 13, 203-212.

PETIT, R. J., BAHRMAN, N. AND BARADAT PH. 1995. Comparison of genetic differentiation in maritime pine (Pinus pinaster Ait.) estimated using isozyme, total protein and terpenic loci. Heredity, 75, 382--389.

RACINE, R. R. AND LANGLEY, C. H. 1980a. Genetic analysis of protein variations in Mus musculus using two-dimensional electrophoresis. Biochem. Genet., 18, 185-197.

RACINE, R. R. AND LANGLEY, C. H. 1980b. Genetic heterozygosity in a natural population of Mus musculus assessed using two-dimensional electrophoresis. Nature, 283, 855-857.

RAMAGOPAL, s. 1990. Protein polymorphism in sugarcane revealed by two-dimensional gel analysis. Theor. Appl. Genet., 79, 297-304.

ROSENBLUM, B. B., NEEL, J. V. AND HANASH, S. M. 1983. Two-dimensional electrophoresis of plasma polypeptides reveals "high" heterozygosity indices. Proc. Natl. Acad. Sci. U.S.A., 80, 5002-5006.

SINGH, R. S. AND COULTHART, M. B. 1982. Genic variation in abundant soluble proteins of Drosophila melanogaster and Drosophila pseudoobscura. Genetics, 102, 437-453.

SMITH, s. C., RACINE, R. R. AND LANGLEY, C. H. 1980. Lack of genic variation in the abundant proteins of human kidney. Genetics, 96, 967-974.

SPICER, G. S. 1988. Molecular evolution among some Drosophila species groups as indicated by two-dimensional electrophoresis. J. Mol. Evol., 27, 250-260.

STAM, P. 1993. Construction of integrated genetic linkage maps by means of a new computer package: JoinMap. Plant J., 3, 739-744.

THATCHER, D. R. 1980. The complete amino acid sequence of three alcohol dehydrogenase alleloenzymes $\left(A d h^{\mathrm{N}-11}\right.$, $A d h^{\mathrm{S}}$ and $A d h^{\mathrm{UF}}$ ) from fruitfly Drosophila melanogaster. Biochem. J., 187, 875-886.

THIELlEMENT, H., SEGUIN, M., BAHRMAN, N. AND ZIVY, M. 1989. Homoeology and phylogeny of the A, S and D genomes of the Triticinae. J. Mol. Evol., 29, 89-94.

TOUZET, P., MORIN, C., DAMERVAL, C., LE GUlllouX, M., ZIVY, M. AND DE VIENNE, D. 1995. Characterizing allelic proteins for genome mapping in maize. Electrophoresis, 16, 1289-1294. 
TSUGITA, A., KAWAKAMI, T., UCHIYAMA, Y., KAMO, M., MIYATAKE, N. AND NOZU, Y. 1994. Separation and characterization of rice proteins. Electrophoresis, 15, 708-720.

DE VIENNE, D., LEONARD1, A. AND DAMERVAL, C. 1988. Genetic aspects of variation of protein amount in Maize and Pea. Electrophoresis, 11, 742-750.

WALTON, K. E., STYER, D. AND GRUENSTEIN, E. 1. 1979. Genetic polymorphism in normal human fibroblasts as analysed by two-dimensional polyacrylamide gel electrophoresis. J. Biol. Chem., 254, 7951-7960.

WILLIAMS, J. G. K., KUBELIK, A. R., LIVAK, K. J., RAFALSKI, J. A. AND TINGEY, s. v. 1990. DNA polymorphisms amplified by arbitrary primers are useful as genetic markers. Nucl. Acid. Res., 18, 6531-6535.
ZIVY, M., THIELlEMENT, H., DE VIENNE, D. AND HOFMANN J.-P. 1984. Study on nuclear and cytoplasmic genome expression in wheat by two-dimensional gel electrophoresis. 2. Genetic differences between two lines and two groups of cytoplasms at five developmental stages or organs. Theor. Appl. Genet., 68, 335-345.

ZIVY, M., DEVAUX, P., BLAISONNEAU, J., JEAN, R. AND THIELLEMENT, H. 1992. Segregation and linkage studies in microspore-derived double haploid lines of Hordeum vulgare L. Theor. Appl. Genet., 83, 919-924.

ZIVY, M., EL MADIDI, s. AND THIELLEMENT, H. 1995. Distance indices in a comparison between the A, D, I and $\mathrm{R}$ genomes of the Triticeae tribe. Electrophoresis, 16, 1295-1300. 